\title{
«Una trompeta lejana». Las Brigadas Internacionales en la guerra de España: Una reconsideración sesenta años después
}

\author{
Michael Alpert *
}

\begin{abstract}
RESUMEN
ABSTRACT

Sin pretender ser una historia de las

This article is not a history of the brigadas Internacionales en la Guerra

Civil Española de 1936-1939, este trabajo se propone examinar ciertos aspectos míticos asociados con las BB.II, en especial la cuestión de su eficacia la experiencia militar de sus jefes. Llega a la conclusión que, aunque el valor y el autosacrificio de los internacionales son innegables, $y$ pese a que se les empleaba a menudo

a las BB./l como fuerzas de choque, su presencia en las fuerzas gubernamentales no pasaba de tener una ejemplaridad moral.

PALABRAS CLAVE Brigadas Internacionales, Guerra Civil. eficacia militar. International Brigades in the Spanish Civil War of 1936 - 1939. It tries to investigate certain persistent myths about the Brigades, in particular the question of their efficiency and the military expertise of their leaders. It concludes that, although the heroism and the self - sacrifice of the Brigades are undeniable, and despite their function as the vanguard in many of the battles, their presence in the Army of the Spanish Republic had a moral influence which far outweighed any military significance.

KEY WORDS International Brigades, Spanish Civil War, military effectiveness.
\end{abstract}

* Catedrático de Historia Moderna y Contemporánea de España, Universidad de Westminster. 


\section{NÚMEROS}

Sigue editándose literatura sobre las Brigadas Internacionales que participaron en la Guerra Civil Española. Sin embargo, tal literatura, escrita desde unos lejanos recuerdos o a base de un dietario, no ha sido siempre tenida en cuenta al redactarse las historias más bien académicas o con intencionalidad política que han ido saliendo. Cualquier crítica de la actuación de las BB.II. arriesga con ser tachada de frío academicismo, de hacer caso omiso de lo heroico del sacrificio de los interbrigadistas e, incluso, de acercarse algo a la actitud de los autores pro-franquistas que dedicaron su esfuerzo a exagerar los números e incluso a denigrar los móviles de los voluntarios.

Precisamente aqui es donde hay que empezar, subrayando que, pese a los exagerados números popularizados con motivos políticos, o calculados empleando métodos de poca fiabilidad, hubo cinco brigadas, es decir, la unidad típica del Ejército de la República, compuesta de cuatro batallones, más (por lo menos en teoría) una gama de servicios de Estado Mayor, Ingenieros, Artillería etc. Como, al llegar el momento de numerar estas brigadas "mixtas", se habian formado ya diez Brigadas Mixtas españolas, se dio a las internacionales los números XI, XII, XIII, XIV y XV inclusive. Por otra parte, más tarde, al alimón de la creciente españolización de las primeras brigadas internacionales, habría batallones internacionales también en unidades españolas, tales como la LXXXVI, la CXXIX y la CL, además de unidades de artillería y de otras especialidades.

Si el cálculo más cuidadoso y fiable arroja una presencia máxima de casi sesenta mil voluntarios internacionales, el número máximo en un momento dado, es decir antes de las grandes pérdidas de las batallas del Jarama y de Brunete de febrero y de julio de 1937, pudo llegar a 35 mil. Es decir que no constituían las BB.II. más que una fracción del Ejército Popular, pese a figurar en todas las campañas, menos la del Norte. En contraste, hubo más italianos (se calcula 73 mil) en el Corpo di Truppe VoIontarie, el CTV que combatió con los sublevados, sin contar el personal italiano de Aviación. Los internacionales eran también menos que los moros Regulares, cuyo total ascendia a más de ochenta mil.

Los brigadistas no fueron los primeros en luchar como voluntarios en el ejército de otro país. Dejando aparte los mercenarios, o regimientos como la Legión inglesa que combatió en España contra los carlistas en los años 1830 , tenemos los ejemplos de individuos tales como el inglés Lord Byron, cuyo sacrificio en el altar de la independencia griega se recordaba a menudo como comparación con los poetas ingleses que murieron por la Re- 
"Una trompeta lejana». Las Brigadas Internacionales en la guerra de España.

pública Española. Más cerca de la época de la guerra civil se recordaba a los estadounidenses y latinoamericanos que llegaron para defender a Francia contra los alemanes en 1914. Entre los mandos de las BB.II. habia ex-militares, sobre todo alemanes y austro-húngaros, que habían luchado en unidades extranjeras defendiendo la revolución soviética contra los fuerzas rusas blancas.

Ninguno de estos ejemplos, sin embargo, corresponde exactamente a los voluntarios que fueron a España en 1936-1937. Debe ser evidente que éstos no eran mercenarios. Admitidamente algunos, sobre todo los franceses que eran mayoritarios entre los extranjeros, se encontraban parados. Otros, muy pocos, posiblemente eran, como los caracterizaba la propaganda franquista "la hez del mundo". Se puede aceptar que algunos muchachos aventureros y alguno que otro marinero que había perdido el barco, se enrolaron en las Brigadas. Sin embargo, la mayoría abandonó empleo y a veces familia para luchar por sus ideales.

A diferencia del CTV italiano y de los moros Regulares franquistas, no existía una estructura militar en la cual recibir a los voluntarios internacionales de la República. La historia de las BB.II. es la de voluntarios ideológicos, que lucharon en unidades con menos organización siquiera que las brigadas españolas del Ejército Republicano, las cuales contaban al menos con algunos militares de carrera.

El nuevo recluta, al presentarse voluntario al Ejército franquista, que poseia el armazón del ejército de pre-guerra, libre de las trabas burocráticas que, paradójicamente, siguieron obstruyendo al Ejército Popular, entraba en un organismo de tradición militar ya existente. En contraste, al llegar los voluntarios internacionales encontraron un organismo todo menos que militar donde la organización, como tal, faltaba. Sin embargo, destacaba en España, desde la llegada misma de las BB.II., y probablemente debido a la marcialidad de los alemanes de los primeros batallones que desfilaron por la Gran Via en Madrid el 8 de noviembre de 1936, el supuesto de que los interbrigadistas poseían disciplina y experiencia militar. En realidad, los personajes extranjeros que mandaron unidades militares en España - Ludwig Renn, Hans Kahle, "Kléber», "Gómez», «Lukács", Dumont, Walter, Cunningham, Copic etc.- eran probablemente excepcionales por haber tenido experiencia militar, y por esto mismo llegaron a puestos de mando.

Para haber tenido dos años de experiencia en la guerra de 1914-1918, un voluntario internacional en España hubiera debido tener en 1936 casi cuarenta años. La mayoria de los voluntarios eran mucho más jóvenes. Entonces, esos alemanes, cuyo paso marcial y voces raucas de mando impresionaron tanto a los observadores españoles que creían que todo lo 
extranjero valía más que un batallón de milicianos españoles bien armados y mandados, probablemente no habían hecho la guerra de 1914-1918 y tampoco el servicio militar, ya que el Tratado de Versalles lo prohibia en Alemania. Los voluntarios italianos, por su parte, exiliados de su país, tampoco habían hecho el servicio militar, y lo mismo podía decirse de aquellos polacos y otros europeos orientales que vivían como refugiados políticos en Francia. En Inglaterra y Estados Unidos no existía el servicio militar. Unicamente los franceses lo habían cumplido. Sin embargo, si muchos de los mandos franceses se describen en las historias de la Guerra Civil como militares de la reserva, esto no quiere decir que fueran militares de carrera sino solamente militares de complemento, es decir que habian hecho el breve servicio establecido desde 1927 en Francia. Las memorias de un inglés, Jason Gurney, adscrito al batallón estadounidense Lincoln, describen la cochambre dejada en las trincheras por un batallón francés. La "experiencia militar" de los interbrigadistas no parecía haberles sido de provecho en España.

\section{URSS Y KOMINTERN}

La Guerra Civil llegó en un momento de máxima dificultad para la URSS y para la Internacional Comunista, la Komintern. La destrucción de la democracia y de los movimientos obreros de Alemania y de Austria, más la creciente agresividad de Mussolini y el resurgimiemto, bajo Hítler, de las fuerzas armadas alemanas, obligaron a Moscú a crear la política del Frente Popular para buscar demostrar a las grandes democracias europeas, Gran Bretaña y Francia, que la URSS no buscaba la revolución fuera de sus fronteras y que era preciso defender los regímenes burgueses contra la amenaza del fascismo y del nacismo.

Tal política no era compartida por todo el movimiento comunista, lo cual había llevado a un conflicto entre la jefatura soviética, en la persona de Stalin, y el máximo representante de la revolución continua, el ya exiliado León Trotski. De modo que, cuando llegó el momento de la guerra española, claramente interpretada como una lucha entre la Izquierda progresiva y la Derecha reaccionaria y fascistizada, si de una parte Moscú prefería minimizar su intervención, limitándola a discursos, colectas, y manifestaciones de masas, por otra la izquierda mundial esperaba de la URSS algo más tangible, sobre todo vista la presencia en España desde el principio del conflicto, de grupos de combatientes extranjeros, formados de exiliados de sus propios países que o vivian ya en España atraídos por la victoria del Frente Popular de febrero de 1936, o llegaron rápidamente 
"Una trompeta lejana". Las Brigadas Internacionales en la guerra de España.

desde Francia para luchar dentro del ambiente del comunismo libertario que se había adueñado de Cataluña y de Aragón.

La decisión de formar una legión de voluntarios se tomó probablemente al final de julio de 1936, como parte del aparato de propaganda de la Internacional. Sin embargo, a la República no le faltaban hombres, sino armas y organización. En un extraño paralelismo con el tratamiento frío dispensado por Franco a los batallones de Camisas Negras enviadas en diciembre de 1936 por Mussolini cuando lo que Franco necesitaba era material, el Gobierno español se mostró evasivo en relación a la proyectada columna de extranjeros.

Al pasar el mes de agosto de 1936, la creciente presencia incontrolada de izquierdistas en España, sobre todo de los que no se adherian a la disciplina comunista, el fracaso militar de las milicias republicanas ante el avance franquista por Extremadura, y el deseo de canalizar la irresistible presión para que la Internacional hiciese algo, llevó a la decisión de reclutar ampliamente, centralizar el reclutamiento en los organismos controlados por el Partido Comunista Francés y de enviar a España a dos personajes importantes del partido comunista francés y del italiano: André Marty y Luigi Longo (a) "Gallo".

Durante este período el Gobierno de José Giral dimitió, siendo sustituído el 4 de septiembre de 1936 por el del socialista Francisco Largo Caballero, que reorganizó el Estado Mayor y efectivamente creó el Ejército de la República. Ya habian llegado a España los elementos más importantes de la embajada rusa, con su séquito de consejeros militares. Precisamente el 15 de octubre de 1936, día de la llegada de la primera gran remesa de material - los carros del coronel Krivoshein en el barco Komsomolempezó Luigi Longo la organización de las Brigadas Internacionales en Albacete. Largo Caballero, el día 22 de octubre, autorizó con poco entusiasmo la constitución de Brigadas Internacionales separadas de las Brigadas Mixtas españolas, con sus propios mandos y organización, viéndolas probablemente como parte del precio a pagar por las armas rusas.

El acuerdo coetáneo entre los países europeos de “No Intervención» en la guerra de España no contemplaba al principio la prohibición de voluntarios, si bien los delegados italiano y alemán en el Comité de No-Intervención no dejaron de quejarse de la afluencia de voluntarios para las Brigadas. Aunque se mantenía cierta discreción en la recluta de voluntarios en, por ejemplo, Inglaterra, esto se debía a la inhibición sentida contra una declaración abierta de que el Partido Comunista, la Internacional y de ahí la URSS, estaban tomando cartas en el asunto español. En realidad, mientras los distintos Gobiernos no legislasen oficialmente para prohibir el viaje a 
España a personas que pensaban ingresar en las Brigadas Internacionales, los voluntarios no contravenian ninguna ley. Abrir un banderín de enganche fuera de España sí podía quizás interpretarse como algo de dudosa legalidad, pero no el facilitar sencillamente el viaje a España a una persona, dándole un billete hasta París, luego unas comidas, una habitación de hotel barato y un billete en el tren 77 - el "tren de los voluntarios"- que cubría el trayecto desde Paris a la frontera española. La URSS por supuesto facilitó el viaje de los aproximadamente quinientos extranjeros que vivian en la URSS, tales como los Manfred Stern "Kleber», Zaisser "Gómez», Zalka "Lukács" y Galicz "Gal» jefes de brigada en España.

El centro escogido era Albacete, centro de comunicaciones de la zona donde se estaban creando a marchas forzadas las nuevas brigadas mixtas del Ejército Popular de la República, lejos del ambiente indisciplinado y peligrosamente desviacionista de Barcelona y de Aragón. Las brigadas internacionales ocuparon la ciudad y pueblos - Mahora, Madrigueras y La Roda- alrededor de ella. Los interbrigadistas recordarían Albacete como una ciudad de poco interés, deprimida, donde ocasionalmente se podía encontrar alimentos guisados más a su gusto que los preparados por los rancheros de las Brigadas.

\section{MADRID}

Los primeros interbrigadistas se habian concentrado, después de cruzar la frontera, en Figueras, desde donde salieron la noche del 12 de octubre. El viaje a Barcelona, luego a Valencia y luego a Albacete, con las demoras naturales en tiempo de guerra y como consecuencia de las recepciones, a veces apoteósicas, ofrecidas por el camino, llevó casi tres días, que mal podían perderse, sobre todo porque en muchos casos los voluntarios llegaron cansados y sufriendo de borracheras, fruto del abundante vino ofrecido en el camino.

Tuvieron poco tiempo para equiparse e instruirse, ya que la situación crítica en la capital de España requirió la presencia urgente de los dos primeros batallones.

Los dos primeros batallones de la XI BI. llegaron a Madrid en la tarde del 7 de noviembre, si bien el mismo día se los mandó estar listos para atacar en dirección al Cerro de los Angeles. Ha habido cierta controversia sobre el momento preciso de la entrada en acción de la XI BI. Ahora bien, las fotografías aparecidas en la prensa del día 9 demuestran que hubo presencia de internacionales en Madrid el día 7. La brigada entró en la 
"Una trompeta lejana". Las Brigadas Internacionales en la guerra de España.

Casa del Campo, trasladándose a la zona de Pozuelo-Humera, aunque casi todos los autores la citan también como presente en las luchas en la misma Casa del Campo. Para el día 13 la XII Brigada Internacional había llegado a Madrid. Su misión era avanzar desde la zona de Pozuelo-Humera sobre Campamento para tratar de envolver las fuerzas sublevadas atacantes. Estos proyectos no llegaron a realizarse, y los diez próximos días vivieron una lucha salvaje y mano a mano para resistir la embestida de los sublevados en la Ciudad Universitaria, adonde llegaron después de haber forzado, el 15-16 de noviembre, el paso del río Manzanares. El desgaste de ambos bandos fue alto. Las dos brigadas internacionales habían luchado denodadamente. Para el 23 de noviembre, cuando los sublevados decidieron poner alto al ataque frontal contra Madrid, las dos BB.II. habian quedado en 2.500 efectivos. La XII había perdido un 30 por 100.

Dada la aureola de propaganda que envolvió a los voluntarios, es difícil confirmar o negar la declaración del historiador militar Martínez Bande, en el sentido de que la llegada de los Internacionales actuó como un "revulsivo para la decaída moral de los milicianos". Sin embargo, hay que subrayar que las dos BB.II. no representaron más que una fracción de las fuerzas de la defensa de Madrid. Por otra parte, sugerir que los internacionales no cambiaron la faz de la batalla o que la capital hubiera resistido sin ellos, no es minimizar ni su generosidad, su idealismo ni su heroísmo, sino reconocer también el esfuerzo de la comandancia de Madrid, de su mando supremo, el general Miaja, de su jefe de Estado Mayor, el coronel Rojo, y de las columnas de milicianos y de las primeras nuevas Brigadas Mixtas del Ejército Popular.

\section{ALREDEDORES}

Una vez retiradas del frente, la XI y la XII Brigadas Internacionales absorbieron nuevos batallones, principalmente franceses e italianos. El invierno de 1936-1937 fue el mómento álgido en cuanto a la velocidad de reclutamiento, por lo cual se pudo formar la XIII y la XIV brigadas, ésta principalmente francófona con los batallones Sans Nom, Vaillant-Couturier, Marseillaise y Henri Barbusse, de los cuales el primero quedó prácticamente destruido en el frente de Córdoba en las Pascuas de Navidades, sobreviviendo 200 de los 700 que habían llegado a Andújar. La primera compañia, principalmente inglesa, del batallón Marseillaise, perdió al escritor Ralph Fox y al joven nieto de Charles Darwin, John Cornford. Fue a consecuencia del desastre que se fusiló el comandante Delassalle, jefe del batallón, aunque quedaron sospechas de que el verdadero motivo del 
castigo había sido la inquina personal sentida contra Delassalle por André Marty, supremo jefe de las Brigadas Internacionales, a quien el mismo Delassalle, oficial de la Deuxième Bureau habia arrestado después del amotinamiento de Marty en el Mar Negro en 1918 cuando unidades de la marina de guerra francesa recibieron órdenes de actuar contra los revolucionarios rusos.

En las batallas alrededor de Madrid, la XI BI resistió desde el 12 hasta el 15 de diciembre la embestida de los sublevados contra Boadilla del Monte, quedando Esmond Romilly, sobrino de Winston Churchill, casi el único sobreviviente de la sección inglesa del batallón Thaelman, que el dia 19 fue aniquilado al lograr, con las otras unidades internacionales, estabilizar el frente.

Empezando el 3 de enero de 1937, los sublevados lanzaron otro ataque hacia el noreste desde Boadilla, buscando cortar la carretera de La Coruña. Ocuparon Las Rozas y Majadahonda, cortando la carretera en varios sitios. Resistieron con determinación, entre otras fuerzas, la X| Brigada Internacional, quedando sólo veinte hombres en el batallón Thaelman, doscientos en el Commune de Paris, y un total de 800 de los 3.500 efectivos con los que había contado la Brigada al entrar en fuego. En los contraataques intervinieron la XII y la XIV traída desde el frente de Córdoba. El ataque empezó con éxito pero en las condiciones meteorológicas imposibles, con niebla y luego nieve, hubo que desistir. Las Internacionales, extenuadas, fueron retiradas a Murcia la XI, al Escorial la XII y a la Zarzuela la XIV. La batalla de la carretera de La Coruña había impedido a los sublevados cerrar la argolla alrededor de Madrid.

\section{REORGANIZACIÓN}

En los batallones Edgar André y Thaelmann de la XI Brigada Internacional quedaban solamente 166 efectivos. Es decir que cuando se habla de la presencia de la XI en sucesivas batallas, no se refiere a los voluntarios originales alemanes, sino a un importante porcentaje de nuevos ingresados y de hasta dos batallones de ef́ectivos españoles. La XIII a su vez recibió un batallón de milicias militarizadas de la Confederación Nacional de Trabajo o CNT, seguramente en un intento de allanar las fricciones políticas entre las fuerzas dirigidas fundamentalmente por comunistas, y la inmensa masa de milicianos anarquistas. La XIV, en cambio, recibió tres batallones de Juventudes Socialistas Unificadas. Con la llegada de los Lincoln estadounidenses, se procedió a formar la XV Brigada Internacional, con los sobrevivientes ingleses de la XIV y un nuevo batallón, pero había que completar la Brigada 
con el Dimitrov y el 6 de février. Se esforzó la jefatura de las Brigadas para aunar unidades de la misma lengua en una brigada. De esta forma, dejando aparte los españoles, la XI hablaba alemán, la XII italiano, la XIII todo un abanico de idiomas balcánicos, la XIV francés y la XV inglés. Ni que decir tiene, que en la historia de las Brigadas Internacionales, la confusión lingüística era responsable de parte del caos reinante, desorden que todas las memorias señalan. Si muchos de los alemanes, italianos y polacos entendian el francés, por haber vivido en aquel país, otros hablaban solamente su propia lengua, sobre todo los ingleses y norteamericanos. Los mandos supremos de las brigadas solian entenderse en ruso, por ser ésta la lengua que tenian en común, ya que la mayoría de ellos, centro-europeos o balcánicos de origen, habian luchado con los soviéticos probablemente después de haber quedado prisioneros de guerra de los rusos en la guerra de 19141918. Hay que tener en cuenta que los internacionales, reacios en general a la disciplina, no pudieron aprender fácilmente no solamente las voces de mando, sino toda suerte de explicaciones, dirigidas por ejemplo por un jefe de batallón, que quizás llevaba 18 años sin interpretar un mapa militar, a jefes de compañía que a lo mejor nunca lo habían hecho. i Cuánta posibilidad de confusión en el fragor de batalla, con mensajes verbales transmitidos por estafetas! ¡ Qué probabilidad de malentendidos en la transmisión de números de unidades, coordenadas de posiciones, siquiera el léxico de los componentes más básicos del equipo militar!

\section{LAS BATALLAS DE 1937}

No intervinieron las Brigadas Internacionales en la primera fase de la batalla del Jarama, que empezó con un ataque lanzado por los sublevados en dirección al este desde sus líneas a caballo de la carretera de Andalucía al sur de Madrid, con la finalidad de cortar la carretera de Valencia. Visto el éxito del ataque de los sublevados, se despachó la XI y la XII Brigadas Internacionales al frente.

El 11 de febrero, por la madrugada, la $2 .{ }^{a}$ compañía del batallón Anóré Marty de la XII BI, atrincherada alrededor del puente del Pindoque, fue sorprendida, debido a su inexperiencia militar, por una unidad de moros regulares y casi completamente destruída, dejando así abierto el paso del río para las fuerzas atacantes.

Esta batalla vio el bautismo de fuego del nuevo batallón inglés de la XV Brigada Internacional. Avanzando hacia San Martín de la Vega, los ingleses se encontraron bajo intenso fuego, retirándose entonces a la cumbre de una colina, que luego bautizaron "la colina del suicidio", donde que- 
daron varias horas defendiéndose contra ataques directos y de flanco. Al fin de la jornada quedaron 125 efectivos de los 400 que había habido en las tres compañías de fusiles, aparte la compañia de ametralladoras, que, dicho sea de paso, había encontrado las cintas de sus Maxims cargadas con balas que no servían, episodio que confirma el mito de profesionalidad militar de las BB.II.. Resistieron hasta el día 12 cuando se retiraron camino de Chinchón. Al norte de los ingleses el batallón estadounidence Lincoln experimentó la guerra por primera vez. Recibida el día 27 la orden de avanzar, sin apoyo aéreo ni artillero, los Lincoln sufrieron 127 muertos y 200 heridos.

La batalla del Jarama fue probablemente el momento cumbre de los internacionales. Luchando valientemente contra un enemigo infinitamente más capacitado para la guerra que ellos, sufrieron hasta 1200 muertos y tres mil heridos.

Donde triunfaron fue en la batalla de Guadalajara, de marzo de 1937, batalla que ha pasado a la historia por ser la primera derrota de los italianos fascistas. En realidad, el interés de Guadalajara, en lo que se refiere a los internacionales, reside en el éxito de los italianos antifascistas, los $\mathrm{Ga}$ ribaldini, en su contra-ataque al avance fascista en el frente de Trijueque, la toma del Palacio de Ibarra y en la reocupación de Brihuega. Aquí triunfaron la ideología y la resolución antifascista contra las tropas mussolinianas, aparentemente bien pertrechadas pero en realidad mal entrenadas, sin apoyo aéreo y sufriendo de una logística caótica que, por una vez, funcionaba peor que la del contrario.

Brunete, de julio de 1937, fue la batalla con más alta participación de las BB.II. que constituyeron hasta la quinta parte de las tropas de la República que intervinieron. La finalidad de la ofensiva republicana era romper las líneas de los sublevados al oeste de Madrid, obligándoles a retirarse hacia la línea del Tajo. Las BB.II. habían sido constituídas en tres divisiones: la 15 mandada por el húngaro Janos Galicz (a) Gal, con la XIII y la XV BB.II.; la 35, mandada por el polaco Wálter, que incluía la XI, en todo caso mitad española y la 45, mandado por Hans Kahle, con la XIII y la CL. más otras unidades internacionales de defensa contra aeronaves, artillería y blindados. Como siempre, las BB.II. fueron empleadas como tropas de choque, sufriendo enormes pérdidas sin verdaderamente demostrar especiales capacidades militares, las cuales en todo caso no se podian pedir a hombres sin experiencia militar y que sólo habían recibido una primitiva formación en Albacete. En los ataques a Quijorna, Villafranca del Castillo, al vértice Romanillos, al vértice Mosquito y a Villanueva del Pardillo, en tierras calcinadas y bajo el sol feroz del verano castellano, 
las bajas de los batallones Henri Vuillemin, Palafox, Dombrowski, Tschapaiev, 6 février, Lincoln, Washington y el británico, fueron muy numerosas teniendo el Lincoln y el Washington que ser fusionados. De 300 ingleses quedaron en pie 42, la XI Brigada perdió 1165, la XII 476, la XIII 1029, teniendo esta unidad que ser disuelta, la XV, 1259, y la CL, 270. La moral, por alta que fuese, no resistía tales pérdidas sin consecuencias tangibles.

\section{CONFLICTOS Y AMOTINAMIENTOS}

En la batalla de Brunete no participó la XIV BI. Esta unidad habia intervenido en el avance hacia Segovia del principio de junio de 1937, descrita por Ernest Hemingway en su célebre novela Por quién tañen las campanas. El ataque fracasó, sufriendo la XIV como castigo una especie de diezmación por negarse a avanzar en dirección a Balsaín y La Granja al haber sufrido grandísimas bajas.

Aquí entramos en el intríngulis de un ejército politizado. En Madrid, al final de noviembre de 1936, el "general" Kléber (es extraordinario que los mandos de las Brigadas Internacionales ostentaran empleos más altos que sus equivalentes en las fuerzas españolas, donde los jefes de milicias no pasaron durante mucho tiempo del empleo de comandante o mayor y donde ningún mando de brigada se titulaba general) fue depuesto del mando de la XI Brigada Internacional a base de una petición formada por el coronel Vicente Rojo, jefe del Estado Mayor de las Defensa de Madrid. Rojo alegó que Kléber no cumplía con las órdenes recibidas y que, además, mentia en sus informes. Estos eran los motivos que se podían alegar oficialmente. En realidad, Kléber consideraba que era función suya no sólo dirigir la XI Brigada Internacional, sino también representar ante el mundo el papel de la Tercera Internacional, el mundo comunista y la URSS en defender la causa del Frente Popular español. Aquí tropezaba con la disciplina seria y callada de Rojo. Kléber se equivocó en su comportamiento, ya que el momento no era para fanfarronerías, y en adelante ningún jefe comunista se salió de su sitio en contra de la disciplina del Ejército de la República y sus jefes profesionales. Kléber, por su parte, terminó siendo devuelto a Rusia, donde desapareció en las purgas de la época. En la Zona Gubernamental, que era lejos de ser una proto-Democracia Popular, como se decía en cierta historiografía de los años cincuenta, quienes dominaban en materia militar, por lo menos en la parte táctica si no en la estrategia, eran los profesionales, como demostrarian muy elocuentemente en marzo de 1939 el éxito del golpe del coronel Casado y la huída de los comunistas. Ahora bien, la constante vigilancia comunista, si por un lado 
se preocupaba por limpiar las Brigadas Internacionales de trotsquistas, no logró detectar los agentes de los varios servicios secretos, sobre todo los de la Deuxième Bureau, incluso Vital Gayman, Jefe de Estado Mayor de la base de Albacete e intimo de André Marty.

\section{DUDOSA EFICACIA}

La marcada característica de las Brigadas Internacionales la constituían las constantes pérdidas, por muerte o heridas, de los jefes de compañia y batallón. El batallón André Marty, por ejemplo, perdió cuatro jefes en dos semanas en la batalla de Madrid. Unidades como las Internacionales, sin armazón militar, eran caracterizadas como ejemplares de la lucha de la izquierda contra el fascismo. Los soldados, faltos de verdadero entrenamiento, esperaban gestos heroicos de sus dirigentes, los cuales, faltos ellos mismos de conocimientos militares, no tenían más remedio que sacrificarse, rodeados de la admiración generalmente sentida por la energía de los comunistas y en el contexto de la ejemplaridad de la guerra de España como conflicto cósmico entre el Bien y el Mal.

Desafortunadamente, la organización y la eficacia de las Brigadas Internacionales no correspondían al entusiasmo y autosacrificio de sus componentes. A pesar de las fotografias de algunos soldados bien uniformados, sobre todo los estadounidenses que se habian equipado completamente en los almacenes de su pais, dando así la impresión de ser los doughboys de 1917 redivivos, la mayoria de los voluntarios eran mal vestidos con restos de uniformes españoles, franceses, y de ropa civil. Hemos visto ya que pocos de los mandos, por lo menos en los niveles de compañia y batallón, tenían experiencia militar. En todo caso, pese al espíritu comunista que dominaba, la mayoría de los voluntarios eran reacios a la necesaria imposición de cierto nivel de disciplina mecánica ¿Quién sabe cuántos fusiles y ametralladoras quedaron inservibles por no limpiarse o revisarse debidamente? ¿Cuántas posiciones se perdieron por un atrincheramiento mal realizado?

Las maniobras básicas de entrenamiento fueron descritas por uno de los voluntarios ingleses como «lo más ineficaz imaginable», sobre todo porque, entre los ingleses por lo menos, el 80 por ciento nunca habían tenido entre sus manos un arma de fuego, ni tenían la preparación física para las duras condiciones de la guerra en España. Al hablar de las armas que recibieron, Jason Gurney describe, cuya ortografía "Shosser" (es en realidad el Chauchat francés), una automática que se encasquillaba constantemente. Las ametralladoras Colt funcionaban pero no así las cintas, de modo 
que no se podía alimentar eficazmente el arma. La punteria de los fusiles rusos exigía dispararlos con la bayoneta fija, maniobra incómoda que pronto se abandonó. $Y$ como ocurría repetidamente en todo el ejército gubernamental, las diferentes armas necesitaban diferentes clases de municiones, lo cual dificultaba una logistica que no brillaba, dada la escasez de profesionales experimentados. Las unidades internacionales eran todo menos bien pertrechadas y entrenadas, como las describió la propaganda hostil de la época. En la XV Brigada ni siquiera el Estado Mayor poseía mapas adecuados de la zona del valle del Jarama donde la brigada iba a luchar.

La sinceridad y la emoción de los voluntarios no se puede poner en entredicho, como tampoco su inmenso sacrificio. Pero militarmente, el hecho de que se les emplease siempre como tropas de choque, no significa que valiesen militarmente más que unidades españolas tales como, entre otras, la 11 división comunista o las 25 y 26 divisiones anarquistas.

\section{FINAL DE LAS BRIGADAS}

Después de luchar en todas las grandes batallas de la guerra civil - Madrid, el Jarama, Brunete, Belchite, Teruel, Aragón y el Ebro-, con una creciente proporción de tropas españolas, las Brigadas Internacionales fueron disueltas en el otoño de 1938. El Dr. Negrín. presidente del Gobierno, esperaba que al cumplir él con la exigencia inglesa de expulsar a los voluntarios extranjeros. Franco también prescindiría de la infantería italiana que servía en su ejército o, si no, Inglaterra y Francia permitirian la venta libre de material de guerra a la República. Los extranjeros de las BB.II. fueron sacados del frente, concentrados en la retaguardia a la espera de la inspección y el recuento que serían realizados por la Comisión Internacional nombrada al efecto.

El 29 de octubre de 1938 tuvo lugar el impresionante desfile final, muy reproducido en los documentales sobre el tema de la Guerra Civil. Luego la comisión internacional verificó la salida de España de los voluntarios extranjeros de la República. Para el 16 de enero de 1939 el informe oficial presentado a la Sociedad de Naciones precisó la cifra de 12.673 personas extranjeras presentes en España. La mayoría de ellas fueron evacuadas durante enero de 1939 aunque quedaron otras hasta la derrota completa de la República.

La visión que la historia tendrá de las Brigadas Internacionales dependerá de la forma en que la historiografía proyecte la Guerra Civil, pero 
nada les restará la generosidad del gesto de esos hombres que dieron, como cantaban los Lincoln en el Jarama, con la melodía del "Red River Valley", su juventud y en algunos casos su vejez también para la causa que defendian.

\section{BREVE BIBLIOGRAFIA}

BRADLEY K. and ChAPPELL M.: International Brigades in Spain 1936-39, Londres, Osprey, 1994. CAStells A.: Las brigadas internacionales de la Guerra de España, Barcelona, Ariel, 1974.

Romilly, E.: Boadilla, London, Hamish Hamilton, 1937. Nueva edición, Macdonald, 1971.

PASELLI L.: “Sul numero e la nazionalità dei volontari antifascisti stranieri nella guerra di Spagna (1936-1939)", Archivo Trimestrale, tomo VIII, N. ${ }^{\circ}$ 1, mayo de 1982.

Richardson T. Dan: Comintern Army: the International Brigades in the Spanish Civil War, Lexington: Kentucky University Press, 1982.

GURNEY J.: Crusade in Spain, Londres, Faber, 1974.

The Roads to Spain: Antifascists at War (compiladores Corkhill D. y Rawmsley S.), Dunfermline, Borderline Press, 1981. 